\title{
Hand grip strength and chronic obstructive pulmonary disease in Korea: an analysis in KNHANES VI
}

\section{Su Hwan Lee \\ Soo Jung Kim \\ Yeji Han \\ Yon Ju Ryu \\ Jin Hwa Lee \\ Jung Hyun Chang}

Division of Pulmonary and Critical Care Medicine, Department of Internal Medicine, Ewha Medical Research Institute, Ewha Womans University School of Medicine, Seoul, Korea
Correspondence: Jung Hyun Chang Division of Pulmonary and Critical Care Medicine, Department of Internal Medicine, Ewha Medical Research Institute, Ewha Womans University School of Medicine, I07I Anyangcheon-ro, Yangcheon-gu, Seoul 07985, Korea

Tel +82 226505686

Fax +82 226502559

Email hs1017@ewha.ac.kr
This article was published in the following Dove Press journal:

International Journal of COPD

4 August 2017

Number of times this article has been viewed

Background: Muscle mass is known to be associated with mortality in elderly adults. Because hand grip strength (HGS) is known as a simple assessment tool for muscular strength, many researchers have studied the association between HGS and disease. However, empirical evidence for the relationship between chronic obstructive pulmonary disease (COPD) and HGS is still controversial. The aim of this study was to evaluate the association between COPD and HGS, using Korean population data.

Methods: This was a population-based cross-sectional study. Data were obtained from the sixth Korean National Health and Nutrition Examination Survey, which was conducted from 2013 to 2015 . To reduce the effects of HGS-related factors and potential confounding factors, propensity score matching was used to match subjects with and without COPD.

Results: Among 14,930 subjects, 832 were enrolled in each group (non-COPD and COPD) after propensity score matching. COPD subjects did not have lower HGS than non-COPD subjects (non-COPD vs COPD, male, $38.0 \pm 7.0$ vs $38.9 \pm 7.0 \mathrm{~kg}, P=0.044$, female, $23.8 \pm 4.6$ vs $24.2 \pm 4.9 \mathrm{~kg}$, $P=0.342$ ). Lung function was classified by Global Initiative for Chronic Obstructive Lung Disease stages and was not significantly associated with HGS. For male COPD subjects, there was a significant correlation between HGS and the EuroQol Five-Dimension Questionnaire (EQ5D) utility score index, which is an indicator of quality of life that adjusts for age and body mass index ( $r=0.201, P<0.001)$. The correlation was absent for female subjects $(r=0.098, P=0.170)$. Conclusion: COPD subjects did not have lower HGS than non-COPD subjects. HGS did not associate with lung function. However, the HGS of male COPD subjects was positively associated with EQ5D utility score index, an indicator of quality of life. HGS may be helpful as an additional method to the evaluation of quality of life in male COPD patients.

Keywords: chronic obstructive pulmonary disease, hand strength, quality of life

\section{Introduction}

Chronic obstructive pulmonary disease (COPD) plays a major role in global morbidity and is expected to be a major cause of death worldwide in $2030 .{ }^{1}$ Progression of COPD often involves worsening dyspnea, decreased quality of life, hospitalization, need for medical resources and increased risk of mortality. ${ }^{2}$ Therefore, it is important to evaluate COPD status for COPD management. The use of forced expiratory volume in 1 second $\left(\mathrm{FEV}_{1}\right)$ has been the severity assessment of choice for COPD; however, reliance on this method has decreased as several other assessment methods have been introduced. ${ }^{1,3,4}$

Cardiorespiratory fitness and muscular strength are associated with mortality and morbidity in several diseases. ${ }^{5,6}$ As an indicator of muscle strength, hand grip strength (HGS), which is a simple measure of upper limb muscle function, has been linked to 
mortality from cardiovascular disease in a large longitudinal population study. ${ }^{7}$ Various comorbidities such as hypertension, coronary artery occlusive disease, stroke and COPD have been associated with low HGS. ${ }^{7}$ Although physical activity is known to be a predictor of mortality in COPD, ${ }^{8,9}$ the association of COPD with HGS is controversial. Some studies have reported that HGS in COPD is unrelated to hospitalization. ${ }^{7}$ In two studies, muscle strength showed no correlation with $\mathrm{FEV}_{1}$ in COPD patients, and muscle strength in these patients was comparable to that of healthy subjects. ${ }^{10,11}$ In contrast, other studies have shown that HGS in COPD is associated with mortality and that subjects with moderate to severe COPD had lower HGS than did healthy subjects. ${ }^{12,13}$

The aim of this study was to evaluate the association between COPD and HGS, after adjusting for comorbidities known to be associated with HGS, using populationbased data from the Korean National Health and Nutrition Examination Survey (KNHANES VI), which was conducted from 2013 to 2015.

\section{Materials and methods Study design and populations}

This used a population-based cross-sectional design. The data were obtained from KNHANES VI, which are nationwide cross-sectional surveys that evaluate the health and nutrition status of Korean populations from 2013 to 2015. Subjects analyzed in this study were aged $>40$ years who completed the questionnaire and performed spirometry between 2014 and 2015. KNHANES VI data contained detailed information on demographics; smoking status; physician-diagnosed comorbidities such as hypertension, stroke, ischemic heart disease and diabetes mellitus (DM); activity limitations; lung function and the EuroQol Five-Dimension Questionnaire (EQ5D) for health-related quality of life.

\section{Definition}

Smoking status was defined as current smoker, ex-smoker or never smoker (smoked $<100$ cigarettes during the lifetime). The several comorbidities included only those diagnosed by physicians. Anemia was defined as $<13 \mathrm{~g} / \mathrm{dL}$ hemoglobin for men and $<12 \mathrm{~g} / \mathrm{dL}$ for women.

\section{Spirometry}

Pulmonary function tests were conducted by trained medical technicians according to the manual of the American Thoracic Society/European Respiratory Society (ATS/ ERS) Task Force, using dry rolling seal spirometers (Model 2130; Sensor Medics, Yorba Linda, CA, USA). ${ }^{14}$ COPD was defined when $\mathrm{FEV}_{1}$ divided by forced vital capacity (FVC) was $<0.7$, in accordance with Global Initiative for Chronic Obstructive Lung Disease (GOLD) guidelines. ${ }^{1}$ The severity of lung function was classified according to the percentage of predicted $\mathrm{FEV}_{1}$. Subjects with $\mathrm{FEV}_{1} \geq 80 \%$ were classified as GOLD stage 1 , those with $50 \% \leq \mathrm{FEV}_{1}<80 \%$ as GOLD stage 2 , those with $30 \% \leq \mathrm{FEV}_{1}<50 \%$ as GOLD stage 3 and those with $\mathrm{FEV}_{1}<30 \%$ as GOLD stage 4 . Subjects with an $\mathrm{FEV}_{1} / \mathrm{FVC} \geq 0.7$ were identified as non-COPD.

\section{HGS}

HGS was measured three times in each hand using a digital grip strength dynamometer (TKK 5401; Takei Scientific Instruments Co., Ltd., Tokyo, Japan). Trained medical technicians instructed the seated subjects to hold the dynamometer with the second finger nodes of the working hand at $90^{\circ}$ to the handle and to squeeze the handle as firmly as they could. After subjects slowly stood up, HGS was measured during expiration. A 60-second rest period was given after each HGS measure. The HGS used in the analysis was the highest of the six measured values. ${ }^{15}$

\section{The EQ5D}

EQ5D was developed by the EuroQol Group to evaluate multidimensional health-related quality of life. ${ }^{16}$ The EQ5D includes a descriptive section and a valuation section; however, KNHANES VI has only been conducted with the descriptive section. The descriptive section includes mobility, self-care, usual activities, pain/discomfort and anxiety/ depression, and each is assessed according to three functional levels: no problems, some problems or extreme problems. The functional level was converted into an EQ5D utility score index using a specific Korean valuation set developed by the time trade-off protocol at the Korean Centers for Disease Control and Prevention. ${ }^{17}$ We analyzed the EQ5D utility score index and descriptive sections for COPD subjects. ${ }^{18}$

\section{Statistical analysis}

All continuous values are described as mean \pm standard deviation, and categorical values are reported as absolute numbers and percentages. The Student's $t$-test and one-way analysis of variance were used for analyzing continuous values. Categorical values were analyzed using the $\chi^{2}$ test or Fisher's exact test. To reduce the effect of HGS-related factors and potential confounding factors, propensity score matching was used to match COPD and non-COPD subjects. The factors of age, sex, body mass index (BMI), cardiovascular disease (including hypertension, dyslipidemia and ischemic 


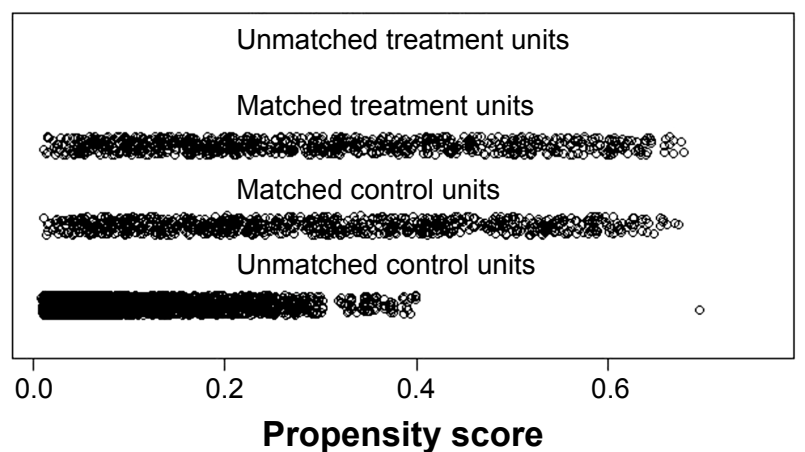

Figure I Distribution of propensity score.

heart disease), stroke, DM and depression were considered during the process of propensity score matching (Figure 1). The Kruskal-Wallis test was used to investigate associations among HGS, EQ5D and lung function in COPD subjects. To assess the association between HGS and EQ5D, a partial correlation analysis was performed to adjust for age and BMI. In all comparisons, a $P$-value of $<0.05$ was considered statistically significant. SPSS version 20 (IBM Corporation, Armonk, NY, USA) was used for the statistical analysis; propensity score matching was performed using the $\mathrm{R}$ program version 3.3.3 for Windows.

\section{Ethics statement}

The KNHANES VI was conducted by the Korea Center for Disease Control and Prevention (KCDC). All survey protocols were approved by the KCDC Institutional Review Board (approval numbers 2013-07CON-03-4CP, 2013-12EXP03-5C and 2015-01-02-6C), and participants provided informed consent before participating in the study, which was conducted in accordance with the ethical principles of the Declaration of Helsinki. All data of KNHANES VI are coded, publicly available and freely available.

\section{Results}

\section{Baseline characteristics of the subjects}

Among the 14,930 subjects, the 5,857 who completed the questionnaire and performed a spirometry adequately were included in this study. Among these, 4,984 (85.1\%) were classified as non-COPD and 873 (14.9\%) had COPD. After propensity score matching, 832 subjects were enrolled in each group. Data for all subjects in both groups were analyzed, except those for whom results for HGS or EQ5D were missing (Figure 2).

Table 1 shows a comparison of the non-COPD and COPD groups. Before propensity score matching, the baseline characteristics of the two groups were very different. The $873(14.9 \%)$ COPD subjects were older and had a higher

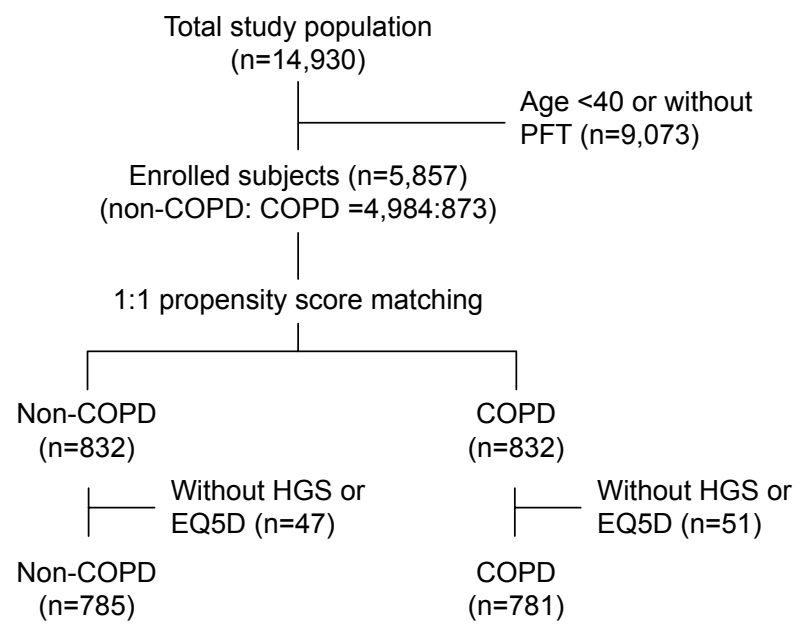

Figure 2 Flow diagram for the study.

Abbreviations: COPD, chronic obstructive pulmonary disease; EQ5D, EuroQol Five-Dimension Questionnaire; HGS, hand grip strength; PFT, pulmonary function test.

proportion of males than did the non-COPD group. COPD subjects also had higher proportions of various comorbidities than did the non-COPD group. Among the subjects with HGS data, male COPD subjects showed lower HGS than did male non-COPD subjects (non-COPD vs COPD $41.7 \pm 7.2$ vs $38.9 \pm 6.9 \mathrm{~kg}, P<0.001)$. A similar pattern of results was observed for female subjects (non-COPD vs COPD 25.7 \pm 4.6 vs $24.2 \pm 4.9 \mathrm{~kg}, P<0.001)$. After propensity score matching, no significant statistical differences remained, except for lung function and smoking status.

\section{Comparison of HGS in non-COPD and COPD groups after propensity score matching}

There was no difference in HGS between non-COPD and COPD groups (non-COPD vs COPD, $34.7 \pm 8.9$ vs $35.2 \pm 8.8 \mathrm{~kg}, P=0.266)$. KNHANES VI data were analyzed by dividing into male and female because each sex had been showed significant difference of baseline HGS in previous studies. ${ }^{7,15}$ For males, there was a statistically significant difference in HGS between non-COPD and COPD subjects, with COPD subjects scoring slightly higher (non-COPD vs COPD, $38.0 \pm 7.0$ vs $38.9 \pm 7.0 \mathrm{~kg}, P=0.044)$. However, there was no such difference among females (non-COPD vs COPD $23.8 \pm 4.6$ vs $24.2 \pm 4.9 \mathrm{~kg}, P=0.342$ ) (Table 2 ).

Figure 3 shows the associations among HGS, EQ5D and lung function in subjects with COPD. Lung function classified as GOLD stages was not significantly associated with either HGS or with EQ5D utility score in either sex. However, there was a significant correlation between HGS and EQ5D utility score in male subjects after adjusting for 
Table I Subject demographics before and after propensity score matching

\begin{tabular}{|c|c|c|c|c|c|c|}
\hline \multirow[t]{2}{*}{ Variables } & \multicolumn{3}{|c|}{ Overall series } & \multicolumn{3}{|c|}{ Propensity score matching } \\
\hline & $\begin{array}{l}\text { Non-COPD } \\
n=4,984\end{array}$ & $\begin{array}{l}\text { COPD } \\
n=873\end{array}$ & $P$-value & $\begin{array}{l}\text { Non-COPD } \\
\mathrm{n}=\mathbf{8 3 2}\end{array}$ & $\begin{array}{l}\text { COPD } \\
n=832\end{array}$ & $P$-value \\
\hline Age, years & $56.3 \pm 10.3$ & $65.3 \pm 9.1$ & $<0.001$ & $64.9 \pm 9.3$ & $65.4 \pm 9.1$ & 0.308 \\
\hline Male sex & I,929 (38.7) & $644(73.8)$ & $<0.001$ & $620(74.5)$ & $606(72.8)$ & 0.436 \\
\hline Height, cm & $160.8 \pm 8.7$ & $164.0 \pm 8.58$ & $<0.001$ & $163.2 \pm 8.3$ & $163.9 \pm 8.62$ & 0.136 \\
\hline $\mathrm{BMI}, \mathrm{kg} / \mathrm{m}^{2}$ & $24.2 \pm 3.1$ & $24.0 \pm 2.8$ & 0.053 & $23.9 \pm 2.8$ & $24.0 \pm 2.8$ & 0.424 \\
\hline HTN & $1,312(26.6)$ & $399(39.2)$ & $<0.00 \mathrm{I}$ & $330(39.7)$ & $338(40.6)$ & 0.689 \\
\hline Dyslipidemia & $956(19.4)$ & $188(21.7)$ & 0.256 & $178(2 \mid .4)$ & $188(22.6)$ & 0.554 \\
\hline Stroke & $92(1.9)$ & $32(3.7)$ & $<0.002$ & $29(3.5)$ & $32(3.8)$ & 0.696 \\
\hline IHD & $125(2.6)$ & $42(5)$ & $<0.001$ & $34(4.1)$ & $42(5)$ & 0.348 \\
\hline DM & $464(9.4)$ & $133(15.4)$ & $<0.00 \mathrm{I}$ & $137(16.5)$ & $132(15.9)$ & 0.739 \\
\hline Arthritis & $792(16.8)$ & $145(17.4)$ & 0.643 & $154(18.5)$ & $145(17.4)$ & 0.566 \\
\hline Depression & $282(5.7)$ & $28(3.2)$ & 0.008 & $35(4.2)$ & $28(3.4)$ & 0.369 \\
\hline Self-reported functional limitation & $379(7.7)$ & $81(9.4)$ & 0.208 & $79(9.5)$ & $81(9.7)$ & 0.833 \\
\hline Ever smoker, n (\%) & I,756 (35.6) & $581(67.2)$ & $<0.001$ & $494(59.4)$ & $551(66.2)$ & 0.004 \\
\hline $\mathrm{FEV}, \%$ of predicted value & $95.1 \pm 11.9$ & $79.6 \pm 15.5$ & $<0.001$ & $96.0 \pm 12.6$ & $79.7 \pm 15.6$ & $<0.001$ \\
\hline GOLD stage I & & $444(50.9)$ & & & $425(5 \mathrm{I} . \mathrm{I})$ & \\
\hline GOLD stage II & & $394(45.1)$ & & & $374(45.0)$ & \\
\hline GOLD stage III & & $35(4.0)$ & & & $33(4.0)$ & \\
\hline
\end{tabular}

Note: Data represented as mean \pm SD or $\mathrm{n}(\%)$.

Abbreviations: BMI, body mass index; COPD, chronic obstructive pulmonary disease; DM, diabetes mellitus; FEV Initiative for Chronic Obstructive Lung Disease; HTN, hypertension; IHD, ischemic heart disease; SD, standard deviation.

age and BMI $(r=0.201, P<0.001)$, while female subjects did not show the correlation $(r=0.098, P=0.170)$.

\section{Relationship between HGS and EQ5D in male subjects with COPD}

Since HGS and the EQ5D utility score index were correlated after adjusting for age and BMI in male COPD subjects, further analyses of the relationship between HGS and EQ5D were performed. Figure 4 shows the statistical significance of analysis EQ5D and male subjects with COPD groups classified as HGS interquartile range. The highest HGS group had higher EQ5D utility scores than did the lowest HGS group $(P<0.001)$. Analyses of groups according to HGS interquartile range and the descriptive section of the EQ5D

Table 2 Comparison of clinical characteristics between non-COPD and COPD subjects

\begin{tabular}{|c|c|c|c|c|c|c|}
\hline \multirow[t]{3}{*}{ Variables } & \multicolumn{3}{|c|}{ Male $(n=I, I 79)$} & \multicolumn{3}{|c|}{ Female $(n=387)$} \\
\hline & Non-COPD & COPD & $P$-value & Non-COPD & COPD & $P$-value \\
\hline & $n=597$ & $\mathrm{n}=\mathbf{5 8 2}$ & & $n=188$ & $n=199$ & \\
\hline Age, years & $64.5 \pm 9.3$ & $65.0 \pm 9.1$ & 0.325 & $66.0 \pm 9.3$ & $65.6 \pm 9.0$ & 0.653 \\
\hline \multicolumn{7}{|l|}{ Age category, years } \\
\hline $40-49$ & $50(8.4)$ & $42(7.2)$ & 0.554 & $12(6.4)$ & $10(5.0)$ & 0.818 \\
\hline $50-59$ & $124(20.8)$ & $110(18.9)$ & & $30(16)$ & $38(19.1)$ & \\
\hline $60-69$ & $248(4 \mid .5)$ & $240(4 \mid .2)$ & & $78(4 \mid .5)$ & 79 (39.7) & \\
\hline$\geq 70$ & $175(29.3)$ & $190(32.6)$ & & $68(36.2)$ & $72(36.2)$ & \\
\hline \multicolumn{7}{|l|}{ Smoking status } \\
\hline Never & $136(22.8)$ & $76(13.1)$ & $<0.00 \mathrm{I}$ & $176(93.6)$ & $183(92)$ & 0.704 \\
\hline Ex-smoker & $328(54.9)$ & $298(5 \mathrm{I} .2)$ & & $8(4.3)$ & $9(4.5)$ & \\
\hline Current & $133(22.3)$ & $208(35.7)$ & & $4(2.1)$ & $7(3.5)$ & \\
\hline Anemia & $55(9.6)$ & $34(6.1)$ & 0.039 & $17(9.6)$ & $17(9.2)$ & 0.905 \\
\hline HGS, kg & $38.0 \pm 7.0$ & $38.9 \pm 7.0$ & 0.044 & $23.8 \pm 4.6$ & $24.2 \pm 4.9$ & 0.342 \\
\hline $\mathrm{FEV}, \%$ of predicted value & $95.3 \pm 12.5$ & $79.5 \pm 14.7$ & $<0.001$ & $98.3 \pm 12.9$ & $80.0 \pm 17.6$ & $<0.001$ \\
\hline \multicolumn{7}{|l|}{ GOLD stage } \\
\hline GOLD I & & $300(5 \mid .5)$ & & & $102(5 \mid .3)$ & \\
\hline GOLD II & & $26 I(44.8)$ & & & $86(43.2)$ & \\
\hline GOLD III, IV & & $21(3.6)$ & & & II (5.5) & \\
\hline
\end{tabular}

Note: Data represented as mean \pm SD or $n(\%)$.

Abbreviations: COPD, chronic obstructive pulmonary disease; SD, standard deviation; HGS, hand grip strength; FEV , forced expiratory volume in I second; GOLD, Global Initiative for Chronic Obstructive Lung Disease. 
A

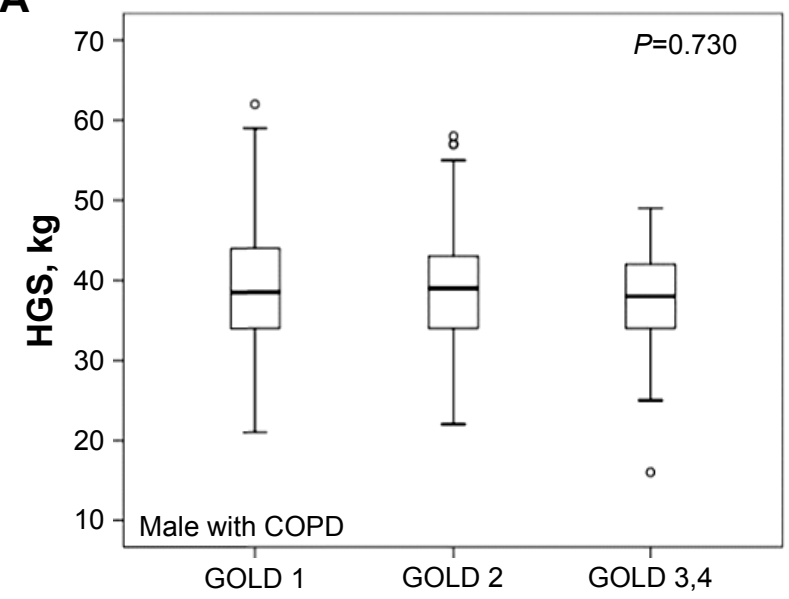

C
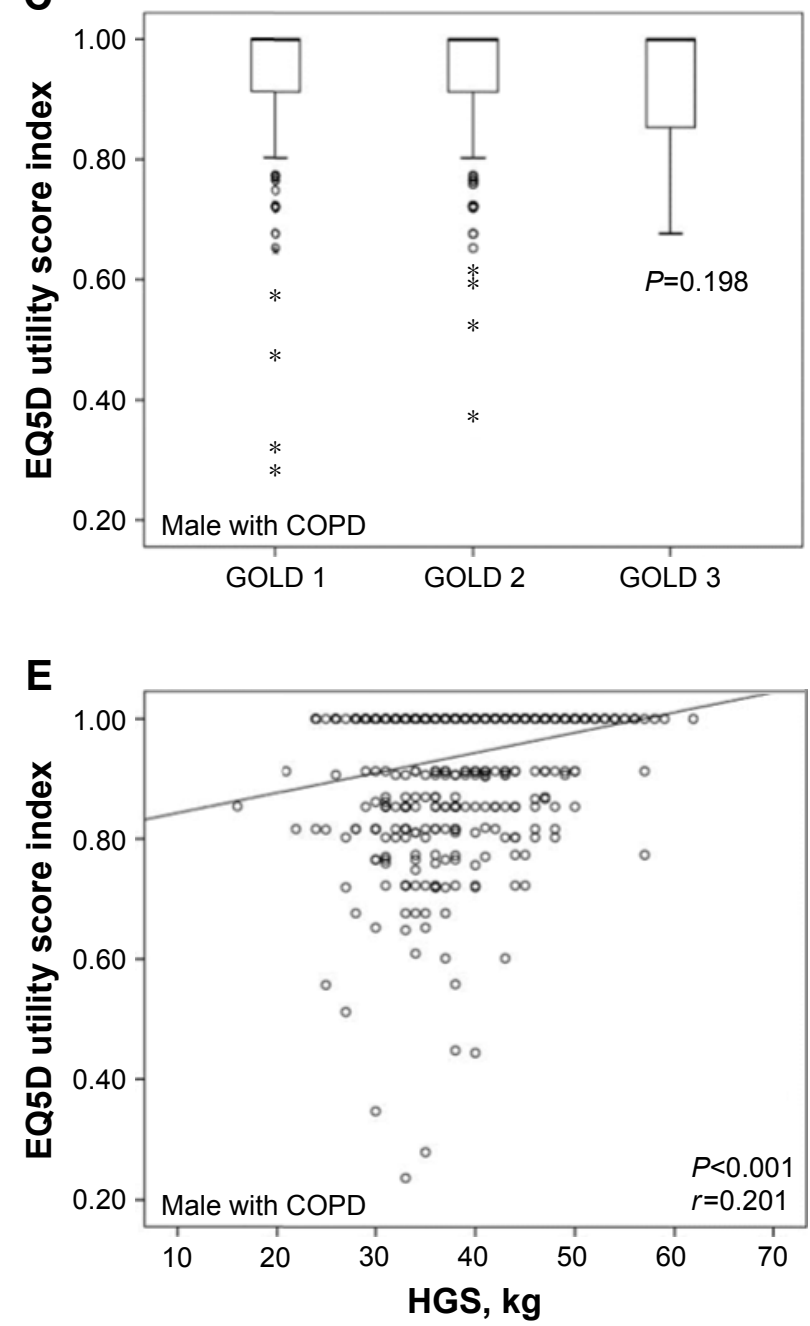

B

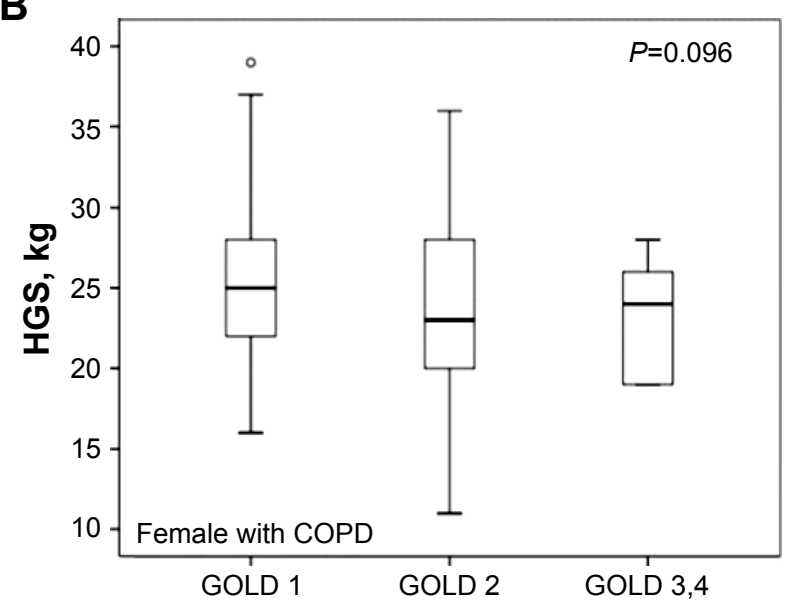

D

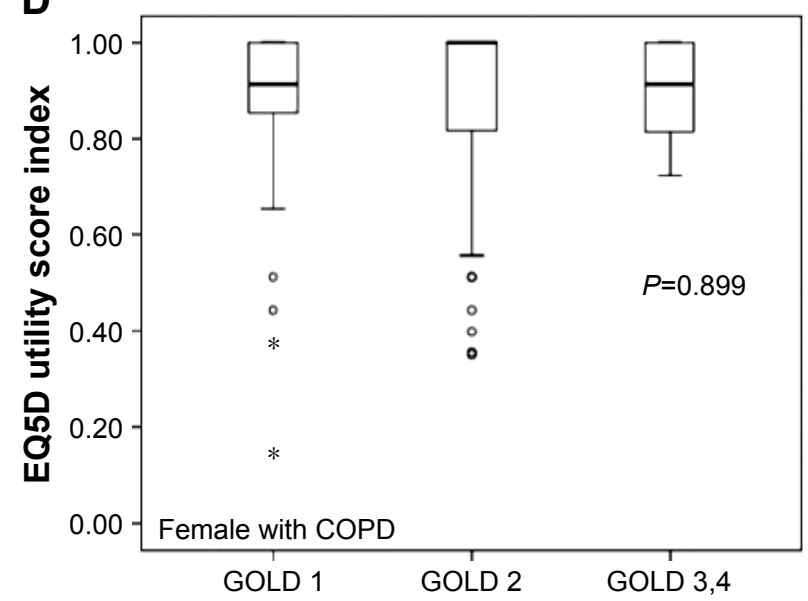

$\mathbf{F}$

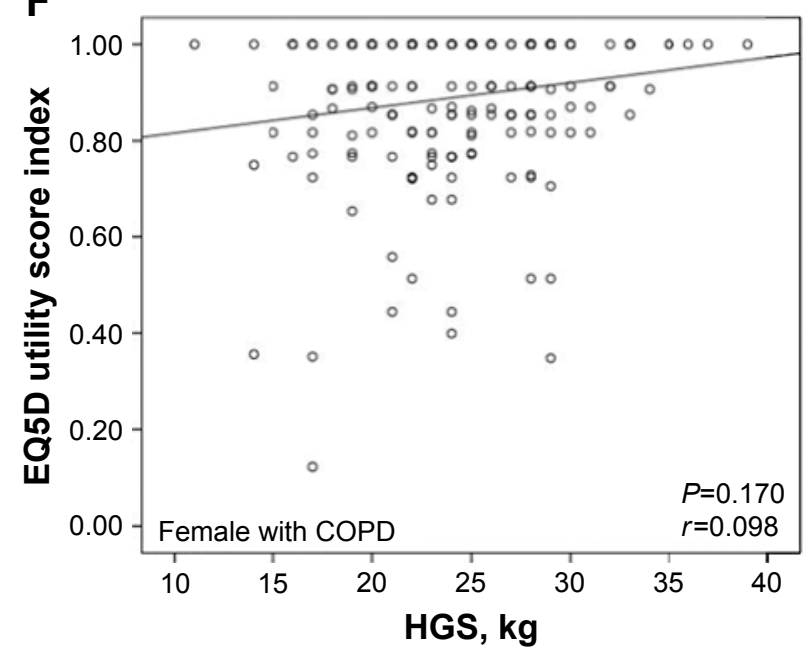

Figure 3 Associations among HGS, EQ5D score and lung function in COPD subjects.

Notes: (A) Association between GOLD stage and HGS in male subjects with COPD. (B) Association between GOLD stage and HGS in female subjects with COPD. (C) Association between GOLD stage and EQ5D utility score in male subjects with COPD. (D) Association between GOLD stage and EQ5D utility score in female subjects with COPD. (E) Correlation between HGS and EG5D utility score in male subjects with COPD after adjusting for age and BMI. (F) Correlation between HGS and EG5D utility score in female subjects with COPD after adjusting for age and BMI. *Indicates a variable that was away from the median.

Abbreviations: COPD, chronic obstructive pulmonary disease; HGS, hand grip strength; EQ5D, EuroQol Five-Dimension Questionnaire; GOLD, Global Initiative for Chronic Obstructive Lung Disease; BMI, body mass index. 


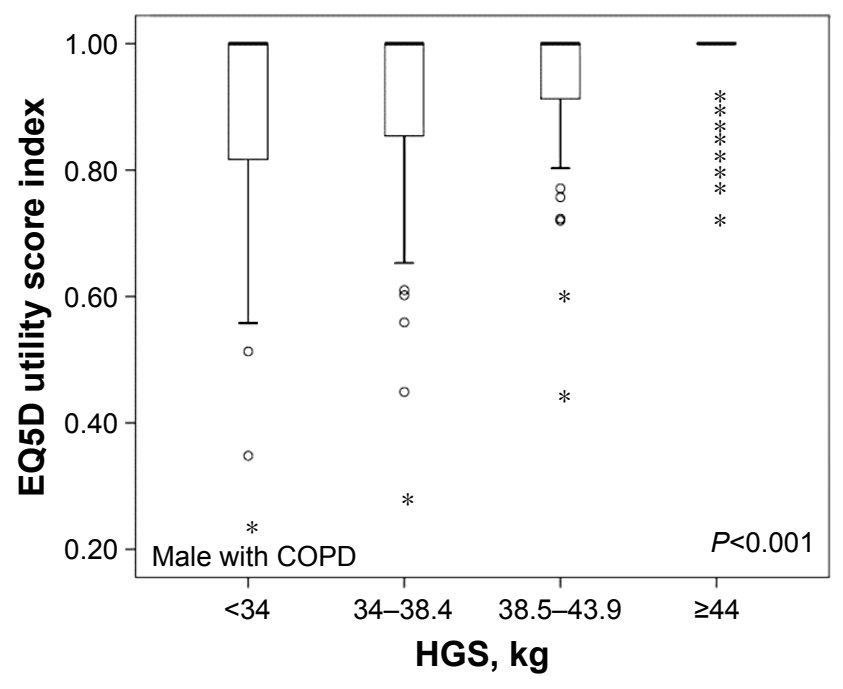

Figure 4 Classification of male subjects according to HGS interquartile ranges and the association with EQ5D utility scores.

Note: *Indicates a variable that was away from the median.

Abbreviations: COPD, chronic obstructive pulmonary disease; HGS, hand grip strength; EQ5D, EuroQol Five-Dimension Questionnaire.

are shown in Table 3. Lower HGS group had problems with mobility, performing usual activities, pain/discomfort and anxiety/depression as well as a lower EQ5D utility score. Only the descriptive section of self-care showed no differences according to HGS.

\section{Relationship between HGS and smoking in male subjects}

The association between smoking and HGS was analyzed because previous studies reported that smoking affects HGS. ${ }^{19,20}$ There were significant difference among never smoker, ex-smoker and current smoker in male subjects who were not considered aged $(37.6 \pm 6.9$ vs $38.2 \pm 6.9$ vs $39.6 \pm 7.2 \mathrm{~kg}, P=0.002)$. However, no significant correlations were observed in groups of male subjects classified as under 65 years or over 65 years (never smoker vs ex-smoker vs current smoker, $41.5 \pm 7.1$ vs $42.4 \pm 6.4$ vs $42.3 \pm 6.7 \mathrm{~kg}, P=0.566$ in age $<65$ years; $35.3 \pm 5.7$ vs $36.0 \pm 6.0$ vs $35.3 \pm 5.4 \mathrm{~kg}$, $P=0.388$ in age $\geq 65$ years). In female subjects, the relationship could not be analyzed due to small sample size in female smoker.

In a subgroup of male COPD subjects, there was no statistical significance among never smoker, ex-smoker and current smoker $(38.2 \pm 7.1$ vs $38.5 \pm 6.7$ vs $39.7 \pm 7.3 \mathrm{~kg}$, $P=0.110)$. In addition, no association was found in EQ5D utility score and smoking status $(P=0.768)$.

\section{Discussion}

This cross-sectional population-based study showed that COPD subjects did not have less HGS than propensity-matched

Table 3 Classification of male subjects according to HGS interquartile ranges and the association with EQ5D utility scores

\begin{tabular}{|c|c|c|c|c|c|}
\hline \multirow[t]{2}{*}{ Variables } & \multicolumn{4}{|l|}{ HGS, kg } & \multirow[t]{2}{*}{$P$-value } \\
\hline & $<34$ & $34-38.4$ & $38.5-43.9$ & $\geq 44$ & \\
\hline \multicolumn{6}{|l|}{ EQ5D descriptive section, n (\%) } \\
\hline \multicolumn{6}{|l|}{ Mobility } \\
\hline No problem & $86(67.2)$ & $122(74.8)$ & I 28 (89.5) & $132(89.2)$ & $<0.001$ \\
\hline Some problem & $40(31.3)$ & $40(24.5)$ & $14(9.8)$ & $16(10.8)$ & \\
\hline Extreme problem & $2(1.6)$ & I (0.6) & I $(0.7)$ & $0(0)$ & \\
\hline \multicolumn{6}{|l|}{ Self-care } \\
\hline No problem & $120(93.8)$ & $154(94.5)$ & $139(97.2)$ & $146(98.6)$ & 0.113 \\
\hline Some problem & $8(6.3)$ & $9(5.5)$ & $4(2.8)$ & $2(1.4)$ & \\
\hline Extreme problem & $0(0)$ & $0(0)$ & $0(0)$ & $0(0)$ & \\
\hline \multicolumn{6}{|l|}{ Usual activities } \\
\hline No problem & $104(81.3)$ & $143(87.7)$ & I 37 (95.8) & $142(95.9)$ & $<0.001$ \\
\hline Some problem & $23(18.0)$ & $20(12.3)$ & $6(4.2)$ & $6(4.1)$ & \\
\hline Extreme problem & I (0.8) & $0(0)$ & $0(0)$ & $0(0)$ & \\
\hline \multicolumn{6}{|l|}{ Pain/discomfort } \\
\hline No problem & 91 (7I.I) & $110(73.6)$ & $119(83.2)$ & $128(86.5)$ & 0.003 \\
\hline Some problem & $34(26.6)$ & $36(22.1)$ & $23(16.1)$ & $20(13.5)$ & \\
\hline Extreme problem & $3(2.3)$ & $7(4.3)$ & I (0.7) & $0(0)$ & \\
\hline \multicolumn{6}{|l|}{ Anxiety/depression } \\
\hline No problem & $112(87.5)$ & I36 (83.4) & I 35 (94.4) & I4I (95.3) & 0.002 \\
\hline Some problem & $15(11.7)$ & $26(16.0)$ & $8(5.6)$ & $7(4.7)$ & \\
\hline Extreme problem & $\mathrm{I}(0.8)$ & $I(0.6)$ & $0(0)$ & $0(0)$ & \\
\hline EQ5D utility score (mean \pm SD) & $0.91 \pm 0.1$ & $0.92 \pm 0.1$ & $0.96 \pm 0.1$ & $0.97 \pm 0.1$ & $<0.001$ \\
\hline
\end{tabular}

Abbreviations: HGS, hand grip strength; EQ5D, EuroQol Five-Dimension Questionnaire; SD, standard deviation. 
non-COPD subjects. In male subjects, those with COPD actually had significantly greater HGS, while there was no difference among females. HGS was also associated with EQ5D in male COPD subjects only.

Some studies have reported that muscle mass was associated with mortality in elderly adults and with functional outcome in critically ill patients. ${ }^{21,22}$ HGS is known as a simple assessment tool for nutritional status, systemic muscle mass and overall muscular strength because of its correlation with several muscular strength measurements such as knee and elbow extension. ${ }^{23-25}$ Therefore, many researchers have studied the association between HGS and mortality and have reported associations between the two. ${ }^{26-28}$ A recent systemic review of HGS has also reported that HGS is associated with increased risk of cardiovascular disease mortality in diverse populations. ${ }^{29}$ One longitudinal study showed that HGS was a predictor of all causes of mortality. ${ }^{26}$ However, the relationships between COPD and HGS in terms of lung function, severity of COPD and mortality are still controversial. ${ }^{10-13}$

In this study, although the HGS of COPD subjects in both sexes were significantly lower than those of non-COPD subjects before propensity score matching, these results were suspected because they did not exclude factors that affect HGS such as cardiovascular disease, age and BMI. After propensity score matching to reduce the effects of several factors, HGS was higher in COPD subjects than in non-COPD subjects, and this finding was statistically significant in males. Cardiovascular disease is known to be associated with HGS, and the observed high prevalence of cardiovascular disease in subjects with COPD before propensity score matching in our study seems to offer at least a partial explanation of the conflicting results. ${ }^{7,13}$ Strandkvist et $\mathrm{al}^{13}$ reported that no difference in HGS between COPD and non-COPD was found and the subjects with cardiovascular disease had significantly lower HGS compared to subjects without cardiovascular disease.

A recent study reported that COPD subjects with GOLD stage 3 or 4 had lower HGS than did non-COPD subjects, ${ }^{13}$ while other studies have shown no correlation between HGS and COPD. ${ }^{10,11}$ In our COPD subjects, there was no significant correlation between HGS and lung function divided by GOLD stage. However, this result is similarly controversial to previous studies because the number of subjects of GOLD stages 3 and 4 in our study is small. ${ }^{10-13}$ Therefore, to confirm the correlation between HGS and lung function, a large population study that considers the factors affecting HGS is needed.
This study showed the association between HGS and COPD in Korea and specifically showed that HGS is correlated with the EQ5D index of quality of life in males with COPD. A similar association between muscle strength and quality of life has been reported in other studies. ${ }^{9,30}$ In our male subjects with COPD, subjects with lower HGS also had significantly lower EQ5D scores. Although the correlation coefficient of HGS and EQ5D utility score calculated from 0 point to 1 point was not high, it seemed clear when comparing the descriptive sections of EQ5D expressed in three functional levels with HGS. In groups classified according to HGS, HGS was negatively associated with problems in all EQ5D sections except self-care. We supposed that the description sections except for anxiety/depression section of the EQ5D involve activities requiring muscle movements; therefore, the association between HGS and EQ5D is to be expected. Furthermore, the EQ5D is indicative of overall quality of life, not dyspnea specifically, and the fact that HGS is not associated with lung function may have affected EQ5D results. In terms of smoking affecting HGS, ${ }^{19,20}$ female COPD might have affected the analysis of HGS due to small sample numbers. However, HGS results according to smoking habits in male COPD subjects showed no association with smoking and HGS. A previous study in Korea reported mean HGS values of $40.2 \mathrm{~kg}$ in males and $24.2 \mathrm{~kg}$ in females, ${ }^{31}$ whereas the corresponding mean values in COPD subjects in our study were 35.77 and $21.76 \mathrm{~kg}$. The relatively greater decrement in HGS of males compared with females in our study might explain the result that the association of EQ5D with HGS was only observed in male subjects with COPD.

This study has the strength of being based on nationwide large-scale data on the relationship between COPD and HGS, which has not been widely studied in Korea. In addition, this study was able to study the association of COPD with HGS more accurately by using the propensity score matching method to adjust for variables other than COPD that are known to be associated with HGS, such as cardiovascular disease and stroke.

This study had some limitations. First, we used the fixed $\mathrm{FEV}_{\mathrm{l}} / \mathrm{FVC}$ criteria of pre-bronchodilator spirometry data. Because subjects did not used bronchodilator, it is possible that asthma subjects were mixed with the COPD subjects. And these cases could represent over-diagnoses of COPD, thereby resulting in misclassification or dilution of the COPD group. ${ }^{32,33}$ Second, the number of samples in the severe COPD group enrolled was low and the evaluation of HGS was limited to mild to moderate COPD group because 
the proportion of COPD patients with GOLD stage 3 or 4 among total subjects was relatively small. Third, there is a limit to the HGS evaluation in female COPD subjects because the number of female subjects was small. Finally, the crosssectional study design presents its own inherent limitations.

\section{Conclusion}

After propensity score matching, COPD subjects in this population-based study did not have lower HGS than nonCOPD subjects. For males, the difference of HGS was statistically significant in subjects with and without COPD and in the unexpected direction; however, there was no difference in HGS in females. In addition, no association was found between HGS and lung function, whether classified as GOLD stage. However, the HGS of male COPD subjects was positively associated with EQ5D, an indicator of quality of life. HGS may be helpful as an additional method to the evaluation of quality of life in male COPD patients.

\section{Disclosure}

The authors report no conflicts of interest in this work.

\section{References}

1. Vestbo J, Hurd SS, Agusti AG, et al. Global strategy for the diagnosis, management, and prevention of chronic obstructive pulmonary disease: GOLD executive summary. Am J Respir Crit Care Med. 2013;187(4): 347-365.

2. Decramer M, Rennard S, Troosters T, et al. COPD as a lung disease with systemic consequences - clinical impact, mechanisms, and potential for early intervention. COPD. 2008;5(4):235-256.

3. Karloh M, Fleig Mayer A, Maurici R, Pizzichini MM, Jones PW, Pizzichini E. The COPD Assessment Test: what do we know so far?: a systematic review and meta-analysis about clinical outcomes prediction and classification of patients into GOLD stages. Chest. 2016;149(2): 413-425.

4. Gupta N, Pinto LM, Morogan A, Bourbeau J. The COPD assessment test: a systematic review. Eur Respir J. 2014;44(4):873-884.

5. Ortega FB, Silventoinen K, Tynelius P, Rasmussen F. Muscular strength in male adolescents and premature death: cohort study of one million participants. BMJ. 2012;345:e7279.

6. Kodama S, Saito K, Tanaka S, et al. Cardiorespiratory fitness as a quantitative predictor of all-cause mortality and cardiovascular events in healthy men and women: a meta-analysis. JAMA. 2009;301(19): 2024-2035

7. Leong DP, Teo KK, Rangarajan S, et al; Prospective Urban Rural Epidemiology (PURE) Study Investigators. Prognostic value of grip strength: findings from the prospective urban rural epidemiology (PURE) study. Lancet. 2015;386(9990):266-273.

8. Waschki B, Kirsten A, Holz O, et al. Physical activity is the strongest predictor of all-cause mortality in patients with COPD: a prospective cohort study. Chest. 2011;140(2):331-342.

9. Troosters T, van der Molen T, Polkey M, et al. Improving physical activity in COPD: towards a new paradigm. Respir Res. 2013;14:115.

10. Marino DM, Marrara KT, Ike D, De Oliveira AD Jr, Jamami M, Di Lorenzo VA. Study of peripheral muscle strength and severity indexes in individuals with chronic obstructive pulmonary disease. Physiother Res Int. 2010;15(3):135-143.
11. Gosselink R, Troosters T, Decramer M. Distribution of muscle weakness in patients with stable chronic obstructive pulmonary disease. J Cardiopulm Rehabil. 2000;20(6):353-360.

12. Burtin C, Ter Riet G, Puhan MA, et al. Handgrip weakness and mortality risk in COPD: a multicentre analysis. Thorax. 2016;71(1):86-87.

13. Strandkvist VJ, Backman H, Roding J, Stridsman C, Lindberg A. Hand grip strength is associated with forced expiratory volume in 1 second among subjects with COPD: report from a population-based cohort study. Int J Chron Obstruct Pulmon Dis. 2016;11:2527-2534.

14. Miller MR, Hankinson J, Brusasco V, et al. Standardisation of spirometry. Eur Respir J. 2005;26(2):319-338.

15. Roberts HC, Denison HJ, Martin HJ, et al. A review of the measurement of grip strength in clinical and epidemiological studies: towards a standardised approach. Age Ageing. 2011;40(4):423-429.

16. Rabin R, de Charro F. EQ-5D: a measure of health status from the EuroQol Group. Ann Med. 2001;33(5):337-343.

17. Lee YK, Nam HS, Chuang LH, et al. South Korean time trade-off values for EQ-5D health states: modeling with observed values for 101 health states. Value Health. 2009;12(8):1187-1193.

18. Nolan CM, Longworth L, Lord J, et al. The EQ-5D-5L health status questionnaire in COPD: validity, responsiveness and minimum important difference. Thorax. 2016;71(6):493-500.

19. Al-Obaidi S, Al-Sayegh N, Nadar M. Smoking impact on grip strength and fatigue resistance: implications for exercise and hand therapy practice. J Phys Act Health. 2014;11(5):1025-1031.

20. Saito T, Miyatake N, Sakano N, et al. Relationship between cigarette smoking and muscle strength in Japanese men. J Prev Med Public Health. 2012;45(6):381-386.

21. Puthucheary ZA, Hart N. Skeletal muscle mass and mortality - but what about functional outcome? Crit Care. 2014;18(1):110.

22. Srikanthan P, Karlamangla AS. Muscle mass index as a predictor of longevity in older adults. Am J Med. 2014;127(6):547-553.

23. Wind AE, Takken T, Helders PJ, Engelbert RH. Is grip strength a predictor for total muscle strength in healthy children, adolescents, and young adults? Eur J Pediatr. 2010;169(3):281-287.

24. Springstroh KA, Gal NJ, Ford AL, Whiting SJ, Dahl WJ. Evaluation of handgrip strength and nutritional risk of congregate nutrition program participants in Florida. J Nutr Gerontol Geriatr. 2016;35(3): 193-208.

25. Granic A, Jagger C, Davies K, et al. Effect of dietary patterns on muscle strength and physical performance in the very old: findings from the Newcastle 85+ study. PLoS One. 2016;11(3):e0149699.

26. Sasaki H, Kasagi F, Yamada M, Fujita S. Grip strength predicts causespecific mortality in middle-aged and elderly persons. Am J Med. 2007; 120(4):337-342.

27. Bohannon RW. Hand-grip dynamometry predicts future outcomes in aging adults. J Geriatr Phys Ther. 2008;31(1):3-10.

28. Bohannon RW. Muscle strength: clinical and prognostic value of handgrip dynamometry. Curr Opin Clin Nutr Metab Care. 2015;18(5): 465-470.

29. Chainani V, Shaharyar S, Dave K, et al. Objective measures of the frailty syndrome (hand grip strength and gait speed) and cardiovascular mortality: a systematic review. Int J Cardiol. 2016;215:487-493.

30. Calik-Kutukcu E, Savci S, Saglam M, et al. A comparison of muscle strength and endurance, exercise capacity, fatigue perception and quality of life in patients with chronic obstructive pulmonary disease and healthy subjects: a cross-sectional study. BMC Pulm Med. 2014;14:6.

31. Yoo JI, Choi H, Ha YC. Mean hand grip strength and cut-off value for Sarcopenia in Korean adults using KNHANES VI. J Korean Med Sci. 2017;32(5):868-872.

32. Roberts SD, Farber MO, Knox KS, et al. FEV1/FVC ratio of $70 \%$ misclassifies patients with obstruction at the extremes of age. Chest. 2006;130(1):200-206.

33. Hwang YI, Kim CH, Kang HR, et al. Comparison of the prevalence of chronic obstructive pulmonary disease diagnosed by lower limit of normal and fixed ratio criteria. J Korean Med Sci. 2009;24(4):621-626. 
International Journal of COPD

\section{Publish your work in this journal}

The International Journal of COPD is an international, peer-reviewed journal of therapeutics and pharmacology focusing on concise rapid reporting of clinical studies and reviews in COPD. Special focus is given to the pathophysiological processes underlying the disease, intervention programs, patient focused education, and self management protocols.

This journal is indexed on PubMed Central, MedLine and CAS. The manuscript management system is completely online and includes a very quick and fair peer-review system, which is all easy to use. Visit http://www.dovepress.com/testimonials.php to read real quotes from published authors 